\title{
Adaptation to Arabic Language, Validity and Reliability Test of Boston Carpal Tunnel Questionnaire in Carpal Tunnel Syndrome Patients
}

\author{
SAMAR A.E. MOHAMMED, M.Sc.; WADIDA H. EL SAYED, Ph.D. and MAGDA R. ZAHRAN, Ph.D. \\ The Department of Basic Science, Faculty of Physical Therapy, Cairo University, Egypt
}

\begin{abstract}
Background: Carpal tunnel syndrome is a frequent cause of compression neuropathy. So, it is necessary to measure function and symptoms which are highly important to patients with carpal tunnel syndrome and have the most impact on quality of life.

Aim of Study: To translate and test face validity, content validity, feasibility, internal consistency reliability and test retest reliability of Arabic-language version of Boston carpal tunnel questionnaire in carpal tunnel syndrome patients.

Material and Methods: Fifty patients with carpal tunnel syndrome was recruited, 95 sheets (test and retest sheets) were filled out, two expert panels (each consists of ten experts) participated in this study. Forward translation, development of preliminary initially translated version, backward translation, and development of the pre-final version and testing of prefinal version by experts then testing of the final version on patients was done. Index of clarity, expert proportion of clearance, index of content validity, expert proportion of relevance, descriptive statistics, missed item index, Cronbach's alpha and Spearman's rank correlation coefficient were used for statistical analysis.
\end{abstract}

Results: The study showed that scale index of clarity equals $87.14 \%$, the mean proportion of clearance equals $87.14 \%$, scale index of content validity equals $96.67 \%$, the mean proportion of relevance equals $96.67 \%$. The questionnaire items were filled by $95 \%$ in all sheets. The questionnaire needed less than 7 minutes to be filled. Cronbach's alpha equals $0.915(0.877,0.915)$ and all Spearman's correlations between test and retest results were statistically significant.

Conclusion: Arabic-language version of Boston carpal tunnel questionnaire has face and content validity, feasibility and Internal consistency and test retest reliability enough in assessment of carpal tunnel syndrome.

Key Words: Validity - Reliability - BCTQ.

\section{Introduction}

PREVIOUSLY, Carpal Tunnel Syndrome (CTS) severity measurements and treatment outcomes

Correspondence to: Dr. Samar A.E. Mohammed,

The Department of Basic Science, Faculty of Physical Therapy, Cairo University, Egypt were assessed by neuromuscular studies and objective signs by physicians, and did not incorporate the patient's perspectives. The Boston Carpal Tunnel Questionnaire (BCTQ), a reliable and valid selfadministered disease-specific outcome questionnaire for CTS. The instrument is disease-specific and covers two important dimensions (function and symptoms) which are highly important to patients with CTS and have the most impact on Quality of Life (QoL) [1]. Many questionnaires of hand function assessment were developed such as: Disability of Arm, Shoulder and Hand Questionnaire (DASH) [2], Michigan Hand Questionnaire (MHQ) [3] and Patient-Related Wrist/Hand Evaluation (PRWHE) [4]. The Boston Carpal Tunnel Questionnaire (BCTQ) is clearly the most promising condition-specific measure. However, the BCTQ has the advantage being a CTS specific instrument and is supported by extensive research in this population [5]. This questionnaire consists of 19 items in two different parts: The Symptom Severity Scale (SSS) and the Functional Status Scale (FSS). The SSS consists of 11 questions that considers wrist pain episodes, numbness, weakness, and difficulty of grasping scored from one (normal) to five (very serious, very difficult, more than five times, and continued). Furthermore, the FSS is an eight itemed subscale which access daily hand functions. The FSS is also scored from one (no difficulty) to five (cannot perform the activity at all). The total score is calculated as the mean of all items for each subscale. Higher scores indicate a worse symptom or function [6]. The BCTQ can be self-, interview-, or telephone-administered the Carpal Tunnel Questionnaire requires $<10$ minutes to complete and does not require special training [1]. Self-administered questionnaires may eliminate bias and, though subjective, are standardized, reproducible and sensitive to clinical changes. In order to use any new assessment tool in research, 
it should be valid and reliable to minimize bias in the study [7].

By adapting an instrument, the researcher is able to equivalence data from different samples and from different backgrounds, which enables greater fairness in the evaluation. The use of adapted instruments enables a greater ability to generalize results and enables one to investigate differences within an increasingly different population [8]. It is important to mention that translation of a valid and reliable scale or questionnaire to any language doesn't mean that this translation is also valid and reliable as the original scale or questionnaire. So validity and reliability testing of the translated version is necessity [8] . Carpal Tunnel Syndrome results from a compression of the median nerve between the transverse carpal ligament, the flexor tendons and the carpal bones at the wrist level and is characterized by paraesthesia, pain, and weakness in the forearm [9]. The diagnosis of CTS is based on the symptoms and signs and Electromyography (EMG) studies. Characteristic symptoms in patients with CTS include nocturnal pain, numbness, and tingling sensation in the radial sides of hands. Tinel's sign and Phalen's sign are common indicators of CTS [10]. Recently, ultrasonography of the median nerve has emerged as an alternative to EMG studies [11,12].

\section{Material and Methods}

Participants: This study was conducted in outpatient clinics of Mansoura University Hospital, Egypt in 2018 to test face validity, content validity, feasibility, internal consistency reliability and test retest reliability of the adapted Arabic-language version of Boston carpal tunnel questionnaire in carpal tunnel syndrome patients. This study followed studies that recommended guidelines for translating, adapting and validating psychological instruments [13,14]. Two expert panels; each consists of ten experts and 50 patients with carpal tunnel syndrome referred by physician participated in this study. Each participant signed the consent form.

\section{Inclusion criteria for experts:}

- Experience not less than ten years or at least master degree.

- Major part of their work is with Arabic population.

- Fluent in Arabic and English.

\section{A- Inclusion criteria for patients:}

All patients were chosen according to the following criteria:

- Referred as carpal tunnel syndrome by physician.
- Being conscious.

- Able to read and write in Arabic.

C-Exclusion criteria for patients:

- Severe neuropathy.

- Wrist trauma or surgery.

- Arthritis.

- Pregnancy.

- Psychological problems.

- Double crush syndrome.

\section{Procedures:}

Initially, the researchers found a various forms of the questionnaire, so, an integrated form was produced from them to suit the Egyptian patient's culture.

\section{The following steps were followed:}

- Forward translation:Translation of the integrated form into Arabic (forward translation or one-way translation) and produce two forward-translated versions (Arl and Ar2).

A- Questionnaire in English was translated into Arabic and produce two forward-translated versions (Arl and Ar2).

B- Two translators were participated in forward translation, their mother language is Arabic, but they had distinct backgrounds.

- One translator was knowledgeable about health terminology and the content area of the construct of the tool in the Arabic.

- The other translator was knowledgeable about the cultural and linguistic nuances of the Arabic.

- Development of the preliminary initial translated Arabic version:

A- Both versions (Arl and Ar2) compared and merged by the researchers.

B- Resolving of discrepancies and linguistic nuances of Arabic language. Then the preliminary initial translated Arabic version developed.

- Blind back-translation (blind backward translation or blind double translation) of the preliminary initial translated version of the questionnaire:

A- The preliminary initial translated Arabic version of the questionnaire was translated into English and produced two back-translated versions (En1 and En2).

B- Two translators participated in back translation, but they had distinct backgrounds. 
- One translator was knowledgeable about health terminology and the content area of the construct of the tool in English.

- The other translator was knowledgeable about the cultural and linguistic nuances of English language.

- Comparison of the two back-translated versions of the questionnaire (En1 and En2):

The researchers compared back-translation of En1 with En2, and also compared both En1 and En2 with the integrated form of the questionnaire regarding instructions, items, response format, wording, sentence structure, meaning and relevance, and they did not need to develop any adjustments to it, so the preliminary initial translated Arabic version considered to be the pre-final Arabic version of the questionnaire.

- Pilot testing 1 of the pre-final Arabic version of the questionnaire for face and content validity:

According to [14], two expert panels participated in this study. Their experience was not less than ten years or at least master degree; their specialties were basic science, orthopedic, neurology and neurosurgery. They evaluated 21 questions of the pre-final Arabic version for face and content validity, first question considering patient data, second question considering questionnaire instructions and 19 questions that were questionnaire items as following:

A- The first expert panel (ten experts) were asked to evaluate each item of the tool for clarity (face validity) and provided suggestions to improve its clarity; dichotomous questions (clear/unclear) was used regarding instruction, items and response words.

B- Then the second expert panel were asked to evaluate each item of the pre-final Arabic version of the questionnaire for content equivalence (content-related validity) using the following scale: 1 =not relevant; $2=$ unable to assess relevance; $3=$ relevant but needs minor alteration; 4=very relevant and succinct and give suggestions to improve its relevance ( 1 and 2 considered not relevant, 3 and 4 considered relevant).

C-After the pre-final version passed expert face and content validity tests, changes suggested were done, it was named the final Arabic Version.

- Pilot testing 2 of the final Arabic version of the questionnaire was conducted on patients with carpal tunnel syndrome: Patients filled out 50 data collection sheets.
- Feasibility (ability to use on larger sample): Feasibility was evaluated by the assessment of the frequency of missing answers per item and administration time.

- Fourty five patients with carpal tunnel syndrome completed the sheet again after two days.

Statistical analysis:

SPSS computer program version 20 (SPSS, Inc., Chicago, IL). Alpha level set at 0.05:

- Face validity was tested by clarity index and expert proportion of clearance.

- Content validity was tested by index of content validity (CVI) and expert proportion of relevance.

- Descriptive statistics of patients and sheets were made.

- Using mean, median, Standard Deviation (SD), mode, minimum (min) and maximum (max).

- Feasibility index was calculated using missed item index and time taken to fill the questionnaire.

- Internal consistency reliability was measured using Cronbach's coefficient alpha.

- Test retest reliability was measured using mean scores and Spearman's rank correlation.

\section{Results}

To test the face validity of Arabic-language version of Boston carpal tunnel questionnaire, item index of clarity was measured. According to the first expert opinion, the index of clarity of all twenty one questions was $87.14 \%$ as shown in (Table 1).

Table (1): Item index of clarity of the final version by the 1 st expert panel.

\begin{tabular}{lcc}
\hline Item number & No of experts agree & Item index of clarity \\
\hline 1 & 7 & $70 \%$ \\
2 & 7 & $70 \%$ \\
3 & 8 & $80 \%$ \\
4 & 7 & $70 \%$ \\
5 & 9 & $90 \%$ \\
6 & 10 & $100 \%$ \\
7 & 10 & $100 \%$ \\
8 & 8 & $80 \%$ \\
9 & 9 & $90 \%$ \\
10 & 9 & $90 \%$ \\
11 & 8 & $80 \%$ \\
12 & 8 & $80 \%$ \\
13 & 8 & $80 \%$ \\
14 & 10 & $100 \%$ \\
15 & 10 & $100 \%$ \\
16 & 10 & $100 \%$ \\
17 & 9 & $90 \%$ \\
18 & 10 & $100 \%$ \\
19 & 8 & $80 \%$ \\
20 & 9 & $90 \%$ \\
21 & 9 & $90 \%$ \\
Mean & & $87.14 \%$ \\
\hline
\end{tabular}


According to expert opinion, the mean value of expert proportion of clarity was $(87.14 \%)$ represented in (Table 2). The second expert panel measured the content validity of the questionnaire and the Scale Index of Content Validity (S-ICV) equaled $96.67 \%$ as shown in (Table 3), also expert proportion of relevance was calculated and represented in (Table 4). Descriptive statistics showed that patients were of both genders (43 female and 7 male) their ages ranged between 25 and 74 years, also it showed that $46 \%$ of participants were house wives and $92 \%$ used their right hand and 45 patients made retest. It also showed that its items were filled by $95 \%$ in all sheets and it needed less than 7 minutes to be answered in about $80 \%$ of all sheets. Internal consistency calculations were made for the final version and it was found that Cronbach's alpha equaled 0.915 , with lower bound 0.877 and upper bound 0.915 at $95 \%$ confidence interval. Spearman's rank correlations were calculated for each item regarding the two-tailed value of $p$ is 0.01 , mean of Spearman's rank correlation was 0.995 as shown in (Table 5).

Table (2): Expert proportion of clearance of the final version by the 1 st expert panel.

\begin{tabular}{lcc}
\hline $\begin{array}{l}\text { Expert } \\
\text { number }\end{array}$ & $\begin{array}{c}\text { No. of items that expert } \\
\text { agree (max. 21 items) }\end{array}$ & $\begin{array}{c}\text { Proportion } \\
\text { of clarity }\end{array}$ \\
\hline 1 & 19 & $90.47 \%$ \\
2 & 21 & $100 \%$ \\
3 & 21 & $100 \%$ \\
4 & 17 & $80.95 \%$ \\
5 & 17 & $80.95 \%$ \\
6 & 21 & $100 \%$ \\
7 & 15 & $71.42 \%$ \\
8 & 12 & $57.14 \%$ \\
9 & 19 & $90.47 \%$ \\
10 & 21 & $100 \%$ \\
Mean & 18.3 & 87.14 \\
\hline
\end{tabular}

Table (3): Item index of content validity of the pre-finalarabic version of the scale by the 2 nd expert panel.

\begin{tabular}{lcl}
\hline Item number & No of experts agree & S-ICV \\
\hline 1 & 10 & $100 \%$ \\
2 & 10 & $100 \%$ \\
3 & 10 & $100 \%$ \\
4 & 10 & $100 \%$ \\
5 & 9 & $90 \%$ \\
6 & 10 & $100 \%$ \\
7 & 9 & $90 \%$ \\
8 & 10 & $100 \%$ \\
9 & 10 & $100 \%$ \\
10 & 10 & $100 \%$ \\
11 & 10 & $100 \%$ \\
12 & 10 & $100 \%$ \\
13 & 10 & $100 \%$ \\
14 & 10 & $100 \%$ \\
15 & 10 & $100 \%$ \\
16 & 10 & $100 \%$ \\
17 & 10 & $1000 \%$ \\
18 & 9 & $90 \%$ \\
19 & 9 & $90 \%$ \\
20 & 9 & $90 \%$ \\
21 & 8 & $80 \%$ \\
Mean & 9.67 & $96.67 \%$ \\
\hline
\end{tabular}

Table (4): Expert proportion of relevance of the final version by the expert panel.

\begin{tabular}{lcc}
\hline $\begin{array}{l}\text { Expert } \\
\text { number }\end{array}$ & $\begin{array}{c}\text { Number of agreements } \\
\text { (relevant responses) }\end{array}$ & $\begin{array}{c}\text { Proportion } \\
\text { of relevance }\end{array}$ \\
\hline 1 & 21 & $100 \%$ \\
2 & 19 & $90.47 \%$ \\
3 & 21 & $100 \%$ \\
4 & 21 & $100 \%$ \\
5 & 21 & $100 \%$ \\
6 & 18 & $85.71 \%$ \\
7 & 21 & $100 \%$ \\
8 & 21 & $100 \%$ \\
9 & 20 & $95.23 \%$ \\
10 & 20 & $95.23 \%$ \\
Mean & 20.3 & $96.67 \%$ \\
\hline
\end{tabular}

Table (5): Spearman's rank correlations coefficients.

\begin{tabular}{lccc}
\hline Item no & $r$-value & $\begin{array}{c}\text { Correlation } \\
\text { strength }\end{array}$ & $\begin{array}{c}\text { Association between } \\
\text { pre- and post-test }\end{array}$ \\
\hline 1 & 0.980 & Very strong & Statistically significant \\
2 & 0.999 & Very strong & Statistically significant \\
3 & 0.999 & Very strong & Statistically significant \\
4 & 0.999 & Very strong & Statistically significant \\
5 & 0.999 & Very strong & Statistically significant \\
6 & 0.994 & Very strong & Statistically significant \\
7 & 0.988 & Very strong & Statistically significant \\
8 & 0.999 & Very strong & Statistically significant \\
9 & 0.997 & Very strong & Statistically significant \\
10 & 0.999 & Very strong & Statistically significant \\
11 & 0.994 & Very strong & Statistically significant \\
12 & 0.999 & Very strong & Statistically significant \\
13 & 0.988 & Very strong & Statistically significant \\
14 & 0.978 & Very strong & Statistically significant \\
15 & 0.999 & Very strong & Statistically significant \\
16 & 0.999 & Very strong & Statistically significant \\
17 & 0.999 & Very strong & Statistically significant \\
18 & 0.999 & Very strong & Statistically significant \\
19 & 0.999 & Very strong & Statistically significant \\
\hline Total score & 0.995 & & \\
\hline
\end{tabular}

\section{Discussion}

The present study was designed to translate and test face validity, content validity, feasibility, internal consistency reliability and test retest reliability of adapted Arabic-language version of the original version of Boston carpal tunnel questionnaire. It is important to mention that translation of a valid and reliable scale or questionnaire to any language doesn't mean that this translation is also valid and reliable as the original scale or questionnaire. So validity and reliability testing of the translated version is necessity [8]. Our study successfully described the Arabic translation and adaptation of the BCTQ and provided excellent analyses of the psychometric properties of the translated questionnaire. Our study concerned with testing of validity and reliability of the whole questionnaire as a one unit, on the other side, other studies tested the validity and reliability of each scale. 
The results demonstrated that the translated BCTQ has acceptable face validity. According to expert's opinion, the index of clarity of all twenty one questions was $87.14 \%$ and the mean value of expert proportion of clarity was $87.14 \%$, also it has excellent content validity as S-ICV equaled $96.67 \%$ and the mean value of proportion of relevance was $96.67 \%$. The results of the current study came in agreement with [15] who stated that a scale to be judged as having excellent content validity, it would be composed of items with item Indexes of Content Validity (I-CVI) that meet the following criteria (I-CVI of 1.00 with three to five experts and a minimum I-CVI of .78 for 6 to 10 experts) and it would have S-CVI of .90 or higher. The recommended standards may necessitate two rounds of expert review if the initial assessment suggests the need for substantial item improvement. Also this came in agreement with [16] who stated that S-CV1/Ave of 0.90 or above is the minimum acceptable index, and items that do not achieve the minimum acceptable indices are revised and reevaluated. The Arabic version of BCTQ had high feasibility because its items were filled by $95 \%$ in all sheets and it needed less than 7 minutes to be answered in about $80 \%$ of all sheets. The results of the current study came in agreement with [17] who stated that missing rate on the item level was considered acceptable if no single item had a missing rate exceeding $10 \%$ and completion time was considered acceptable if $95 \%$ of sheets were completed in less than 15 minutes. The Arabic version of BCTQ had very good internal consistency and very good test retest reliability as Cronbach's alpha was found to be $0.915(0.877,0.915)$ and all spearman's rank correlation coefficients between test and retest results were statistically significant as $r=0.995$ (item 1:0.980, item 2:0.999, item 3:0.999, item 4:0.999, item 5:0.999, item 6: 0.994, item 7:0.988, item 8:0.999, item 9:0.997, item 10:0.999, item 11:0.994, item 12:0.999, item 13:0.988, item 14:0.978, item 15:0.999, item 16: 0.999, item 17:0.999, item 18:0.999, item 19:0.999. So according to [18] a between 0.7 and 0.9 is referred as good internal consistency, also Spearman's rank correlation coefficient between $0.7, \mathrm{cc}$ and 0.9 (as in item 1, 3, 4, 5 and 6) is referred as good test retest reliability and Spearman's rank correlation coefficient between 0.6 and 0.7 (as in item 2 and 7) is referred as acceptable test retest reliability. Similar results for the original English version of the BCTQ for internal consistency have been reported ( 0.89 and 0.91 for each scale) and for correlation coefficients in test-retest reliability measurements ( $r=0.91$ and $r=0.93$ for the SSS and the FSS, respectively) [1].
Likewise, the Greek version of the questionnaire showed high reliability index expressed through Cronbach a 0.89 (for SSS) and 0.93 (for FSS), with moderate to high correlation coefficient ( $r=$ 0.53 for SSS and 0.68 for FSS) [19]

Also the results came in agreement with the Spanish version of BCTQ. Reliability was very good, internal consistency: a $\mathrm{S}=0.91$ and $\mathrm{aF}=0.87$; test-retest stability: $\mathrm{rS}=0.939$ and $\mathrm{rF}=0.986$ [20] These results also came in agreement with the study of the Korean version K-BCTQ of the questionnaire. The ICCs were 0.92 for the SSS and 0.94 for the FSS. The Cronbach's alpha coefficients of the K-BCTQ ( 0.89 for the SSS and 0.90 for the FSS) are indicative of the high internal consistency other questionnaire [21]. Internal consistency was determined using the Cronbach's alpha coefficients of inter-item correlations. A Cronbach's alpha of 1.0 represents a perfect correlation among all items [1] , and a Cronbach's alpha of >_0.7 is considered to indicate satisfactory internal consistency [22] An ICC value of $>0.75$ indicates that an instrument is reliable [23]. A project to translate, adapt and validate an instrument for cross-cultural research may take several years; and it is normally conducted using more than one study to adhere to the recommended methodological approaches described above [14]

One study might set as its initial goal to translate, adapt and cross-validate a research instrument using translation steps and pilot testing of the prefinal version of the instrument in the target language with a monolingual sample: cognitive debriefing [14].

In a second study, the researchers might set a single goal to establish the preliminary psychometrics of the translated instrument with bilingual participants. Then, in a third study, the researchers' goal might be to establish the initial full psychometric properties of a translated instrument in a sample of the target population of interest [14]. The final version is considered the base for the next research that will be conducted to establish the full psychometric properties of Arabic-language version of BCTQ.

\section{Conclusion:}

The results obtained from the current study and the discussion that followed it can lead to concluding that Arabic-language version of Boston carpal tunnel questionnaire has face and content validity, feasibility and internal consistency and test retest reliability enough in assessment of carpal tunnel syndrome. 


\section{References}

1- LEVINE D.W., SIMMONS B.P., KORIS M.J., DALTROY L.H., HOHL G.G., FOSSEL A.H. and KATZ J.N.: A selfadministered questionnaire for the assessment of severity of symptoms and functional status in carpal tunnel syndrome. J. Bone Joint. Surg. Am., 75: 1585-92, 1993.

2- CHATTERJEE J.S. and PRICE P.E.: Comparative Responsiveness of the Michigan Hand Outcomes Questionnaire and the Carpal Tunnel Questionnaire After Carpal Tunnel Release. The J. of Hand Surg., 34: 273-80, 2009.

3- CHUNG K.C., PILLSBURY M.S., WALTERS M.R. and HAYWARD R.A.: Reliability and validity testing of the Michigan Hand Outcomes Questionnaire. Journal of Hand Surgery, 23: 575-87, 1998.

4- WAH J.W., WANG M.K. and PING C.L.: Construct validity of the Chinese version of the patient-rated wrist evaluation questionnaire (PRWE-Hong Kong version). Hand Ther., 19: 18-26, 2006.

5- SAMBANDAM S.N., PRIYANKA P., GUL A. and ILANGO B.: Critical analysis of outcome measures used in the assessment of carpal tunnel syndrome. Int. Orthop. Mar. 17, 2007.

6- LUE Y.J., LU Y.M., LIN G.T. and LIU Y.F.: Validation of the chinese version of the boston carpal tunnel questionnaire. J. Occup. Rehabil., 24 (1): 139-45, 2014.

7- KIMBERLIN C.L. and WINTERSTEIN A.G.: Validity and Reliability of Measurement Instruments Used in Research. American Journal of Health-System Pharmacists, 65 (1): 2276- 84, 2008.

8- HAMBLETON R.K.: Issues, designs, and technical guidelines for adapting tests into multiple languages and cultures. In R.K. Hambleton, P.F. Merenda, \& C.D. Spielberger (Eds.), Adapting educational and psychological tests for cross-cultural assessment (pp. 3-38). Mahwah, NJ: Lawrence Erlbaum, 2005.

9- ALFONSO C., JANN S., MASSA R., et al.: Diagnosis, treatment and follow-up of the carpal tunnel syndrome: A review. Neurological Sciences, 31: 243-52, 2010.

10- JABLECKI C.K., ANDARY M.T., FLOETER M.K., MILLER R.G., QUARTLY C.A., VENNIX M.J. and WILSON J.R.: American Association of Electrodiagnostic Medicine; American Academy of Neurology; American Academy of Physical Medicine and Rehabilitation. Practice parameter: Electrodiagnostic studies in carpal tunnel syndrome: Report of the American Association of Electrodiagnostic Medicine, American Academy of Neurology, and the American Academy of Physical Medicine and Rehabilitation. Neurology, 58: 1589-92, 2002.

11-YESILDAG A., KUTLUHAN S., SENGUL N., KOYUNCUOGLU H.R., OYAR O., GULER K., et al.: The role of ultrasonographic measurements of the median nerve in the diagnosis of carpal tunnel syndrome. Clin. Radiol., 59: 910-5, 2004.

12- ZISWILER H.R., REICHENBACH S., VÖGELIN E., BACHMANN L.M., VILLIGER P.M., et al.: Diagnostic value of sonography in patients with suspected carpal tunnel syndrome: A prospective study. Arthritis Rheum., 52: 304-11, 2005

13- BORSA J.C., DAMASIO B.F. and BANDEIRA D.R.: Cross-Cultural Adaptation and Validation of Psychological Instruments: Some Considerations. Paideia, 22: 423-32, 2012.

14- SOUSA V. and ROJJANASRIRAT W.: Translation, adaptation and validation of instruments or scales for use in cross-cultural health care research: A clear and user friendly guideline. Journal of Evaluation in Clinical Practice, 17 (2): 268-74, 2011.

15- POLIT D. and BECK C.: The content validity index: Are you sure you know what's being reported? Critique and recommendations. Nurs. Health, 29 (5): 489-97, 2006.

16- WALTZ C., STRICKLAND O. and LENZ E.: Measurement in Nursing and Health Research, 3re edition. New York; Springer Publishing Company, 2005.

17- VAN V., BIRNIE E., POERAN J., TORIJ H., STEEGERS E., BONSEL G., et al.: Feasibility and reliability of a newly developed antenatal risk score card in routine care. Midwifery, 31: 147-54, 2015.

18- GEORGE D. and MALLERY P.: SPSS for Windows step by step: A simple guide and reference, 11.0 updarte, 4 th edition. Boston: Allyn and Bacon, 2003.

19-BOUGEA A., ZAMBELIS T., VOSKOU P. and KATSIKA P.Z.: Reliability and Validation of the Greek Version of the Boston Carpal Tunnel Questionnaire. Hand (NY), 13 (5): 593-9, 2018.

20- OTERO-ALVARO A., MARÍN M.T., MATAS J.A., et al.: Spanish validation of the Boston Carpal Tunnel Questionnaire. Med. Clin. (Barc), 146 (6): 247-53, 2016.

21- KIM J.K. and LIM H.M.: The Korean version of the carpal tunnel questionnaire. Cross cultural adaptation, reliability, validity and responsiveness. J. Hand Surg. Eur. Vol., 40 (2): 200-5, 2015.

22- ROH Y.H., YANG B.K., NOH J.H., BAEK G.H., SONG C.H., et al.: Cross-cultural adaptation and validation of the Korean version of the Michigan Hand Questionnaire. J. Hand Surg. Am., 6: 1497-503, 2011.

23- NAVARRO C.M., PONZER S., TORNKVIST H., AHRENGART L., et al.: Measuring outcome after wrist injury: Translation and validation of the Swedish version of the patientrated wrist evaluation (PRWE-Swe). B.M.C. Muscul. Dis., 12, 2011. 


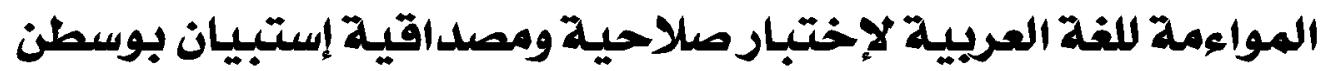 على مرضى متحلازمة الجنفق الرحسفى}

الخلفية العلمية: تتجم متلازمة النفق الرسغى عن إنضغاط العصب المتوسط على مستوى النفق الرسغى في الرسنغ، وهو سبب متكرر

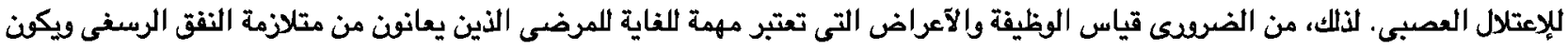
لها آكبر تآثير على نوعية المياة.

هدف البحث: يهدف هذا البحث إلى ترجمة وإختبار الصلاحية الظاهرية وصلاحية المحتوى والجلوى والتناسق الداخلى والثبات للنسخة

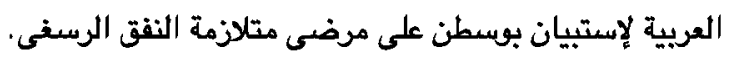

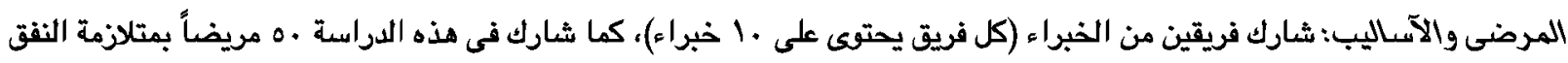

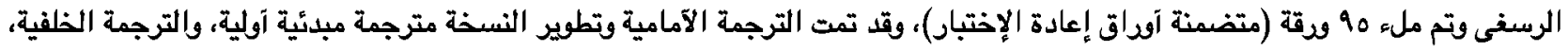

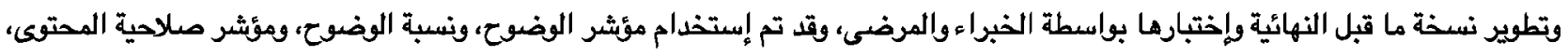

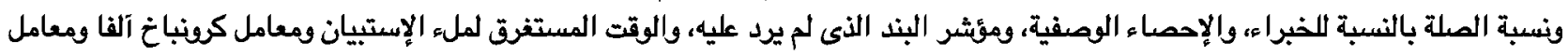
إرتباط سبيرمان التحليل الإحصائى.

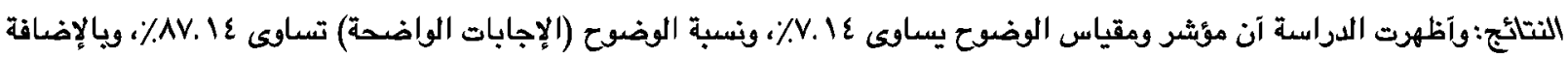

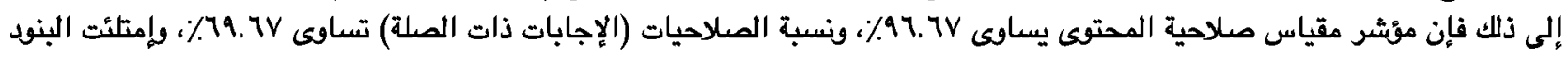

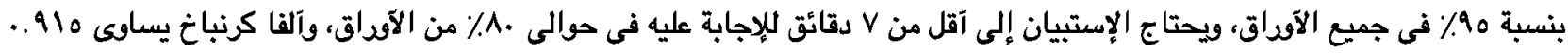

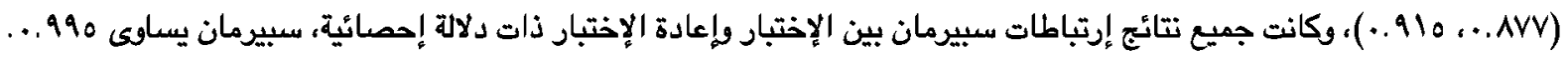
الإستتاج: نستتتج آن النسخة العربية من إستبيان بوسطن لمرضى متلازمة النفق الرسفى ذو صلاحية ظاهرية وداخلية وذو جدوى وذو

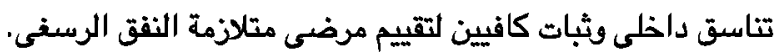

